\title{
A DISCRETE ECONOMIC GROWTH MODEL WITH ENDOGENOUS LABOR
}

\author{
WEI-BIN ZHANG
}

Received 11 October 2004 and in revised form 28 December 2004

This paper proposes an alternative approach to economic growth with endogenous labor supply. The production side is the same as the Solow model, the Ramsey model, and the Diamond model. But we deal with the behavior of consumers differently from the traditional approaches by proposing a concept of disposable income (which is the sum of the wealth available for use, the current income from interest income, and the wage payment) and a utility function which depends on the current consumption, savings, and leisure. The model provides a mechanism of endogenous saving and labor supply which the Solow model lacks, avoids the assumption of adding up utility over a period of time upon which the Ramsey approach is based, and does not need the assumption of two-period agents which the Diamond model and many of its extensions accept.

\section{Introduction}

There are three main frameworks in modeling economic growth with capital accumulation. The Solow model is the starting point for almost all analyses of economic growth, see Solow [6]. Nevertheless, the Solow model does not provide a mechanism of endogenous savings. Ramsey's optimal growth theory [4] has influenced modeling of consumers' behavior since the late 1960's. This approach assumes that utility is addable over time. In his original contribution to growth theory with capital accumulation, Diamond [3] used the overlapping-generations structure as proposed by Samuelson [5] to examine the long-term dynamical efficiency of competitive production economies. The model has become a standard tool in macroeconomics to study economic dynamics in discrete time. Many growth models of macroeconomics are built within the OLG framework. A common assumption of the approach is that agents live only two periods-as mentioned by Azariadias [1], each period should last over 30 years if one really wants to use analytical results to provide direct insights into reality. The length of over 30 years period is generally considered too long for discussing economic changes because within each period nothing is allowed to be changeable. These seminal papers were technically refined and generalized in different ways over years, and many other factors, such as home production, labor supply (and leisure), human capital, population growth, and innovation, have 
been introduced into these analytical frameworks. This study proposes an alternative way in modeling behavior of consumers with endogenous saving and labor supply. The paper is organized as follows. Section 2 defines the model. Section 3 proves that the dynamic system has a unique stable equilibrium point. Section 4 examines effects of changes in technology and preference on economic growth and labor supply. Section 5 concludes the study.

\section{The model}

This section builds a growth model with endogenous saving and leisure time in discrete time. The economy has an infinite future. We represent the passage of time in a sequence of periods, numbered from zero and indexed by $t=0,1,2, \ldots$. The end of period $t-1$ coincides with the beginning of period $t$; it can also be called period $t$. We assume that transactions are made in each period. The population, $N$, is constant. Most aspects of our model are similar to the Solow one-sector growth model, see Solow [6], Burmeister and Dobell [2]. The discrete version of the Solow model is referred to by Diamond [3] and Azariadis [1]. It is assumed that there is only one (durable) good in the economy under consideration. Households own assets of the economy and distribute their incomes to consume and save. Exchanges take place in perfectly competitive markets. Production sectors sell their product to households or to other sectors and households sell their labor and assets to production sectors. Factor markets work well; the available factors are fully utilized at every moment. Saving is undertaken only by households, which implies that all earnings of firms are distributed in the form of payments to factors of production, labor, managerial skill, and capital ownership.

We assume perfect competition in all markets and select commodity to serve as numeraire, with all the other prices being measured relative to its price. Let $K(t)$ denote the capital existing in period $t$, and $N(t)$ the flow of labor services used at time $t$ for production. The total labor force $N(t)$ is given by $N(t)=T(t) N_{0}$, where $T(t)$ is the work time of a representative household and $N_{0}$ is the population. In this study, we assume $N_{0}$ to be fixed. As our model exhibits constant returns to scale, the dynamics (in terms of capita) will not be affected if we allow the population to change at a constant growth rate over time.

We use the conventional production function to describe a relationship between inputs and outputs. The function $F(t)$ defines the flow of production at time $t$. The production process is described by some sufficiently smooth function, $F(t)=F(K(t), N(t))$. We assume that $F(K(t), N(t))$ is neoclassical. Introduce $f(k(t)) \equiv F(k(t), 1)$, where $k(t) \equiv$ $K(t) / N(t)$. The function $f$ has the following properties: (i) $f(0)=0$; (ii) $f$ is increasing, strictly concave on $\mathbb{R}^{+}$, and $C^{2}$ on $\mathbb{R}^{++} ; f^{\prime}(k)>0$ and $f^{\prime \prime}(k)<0$; (iii) $\lim _{k \rightarrow 0} f^{\prime}(k)=\infty$ and $\lim _{k \rightarrow+\infty} f^{\prime}(k)=0$. Let $\delta_{k}$ denote the fixed rate of capital depreciation. Markets are competitive; thus labor and capital earn their marginal products, and firms earn zero profits. We assume that the output good serves as a medium of exchange and is taken as numeraire. The rate of interest and wage rate are determined by markets. Hence, for any individual firm, $r(t)$ and $w(t)$ are given at each point of time. The production sector chooses the two variables $K(t)$ and $N(t)$ to maximize its profit. The marginal conditions 
are given by

$$
r(t)+\delta_{k}=f^{\prime}(k(t)), \quad w(t) \equiv f(k(t))-k(t) f^{\prime}(k(t)) .
$$

Consumers make decisions on choice of consumption levels of services and commodities as well as on how much to save. In order to provide proper description of endogenous savings, we should know how individuals perceive the future. Different from the optimal growth theory in which utility defined over future consumption streams is used, we do not explicitly specify how consumers depreciate future utility resulting from consuming goods and services. We assume that we can find preference structure of consumers over consumption and saving at the current state.

Let $k^{*}(t)\left(\equiv K(t) / N_{0}\right)$ stand for per capita wealth. According to the definition of $k(t)$ and $k^{*}(t)$, we have $k^{*}(t)=k(t) T(t)$. Per capita current income from the interest payment $r(t) k^{*}(t)$ and the wage payment $w(t) T(t)$ is given by

$$
y(t)=r(t) k^{*}(t)+w(t) T(t)
$$

We call $y(t)$ the current income in the sense that it comes from consumers' daily toils (payment for human capital) and consumers' current earnings from ownership of wealth. The current income is equal to the total output as we neglect any taxes at this initial stage. The sum of money that consumers are using for consuming, saving, or transferring is not necessarily equal to the temporary income because consumers can sell wealth to pay, for instance, the current consumption if the temporary income is not sufficient for buying food and touring the country. Retired people may live not only on the interest payment but also have to spend some of their wealth. The total value of wealth that consumers can sell to purchase goods and to save is equal to $k^{*}(t)$. Here, we assume that selling and buying wealth can be conducted instantaneously without any transaction cost. The per capita disposable income is given by

$$
\hat{y}(t)=y(t)+k^{*}(t)
$$

The disposable income is used for saving and consumption. At each point of time, a consumer would distribute the total available budget among savings $s(t)$ and consumption of goods $c(t)$. The budget constraint is given by

$$
c(t)+s(t)=\hat{y}(t)=r(t) k^{*}(t)+w(t) T(t)+k^{*}(t) .
$$

Denote by $T_{h}(t)$ the leisure time at time $t$ and denote the (fixed) available time for work and leisure by $T_{0}$. The time constraint is expressed by

$$
T(t)+T_{h}(t)=T_{0} .
$$

Substituting this function into the budget constraint yields

$$
w(t) T_{h}(t)+c(t)+s(t)=\bar{y}(t) \equiv r(t) k^{*}(t)+w(t) T_{0}+k^{*}(t) .
$$

In our model, at each point of time, consumers have three variables to decide. We assume that the utility level $U(t)$ that the consumers obtain is dependent on the leisure time $T_{h}$, 
104 A discrete economic growth model with endogenous labor

the consumption level $c(t)$ of commodity, and the savings $s(t)$ as follows:

$$
U(t)=T_{h}^{\sigma}(t) c^{\xi}(t) s^{\lambda}(t), \quad \sigma, \xi, \lambda>0, \sigma+\xi+\lambda=1,
$$

where $\sigma$ is called the propensity to use leisure time, $\xi$, the propensity to consume, and $\lambda$, the propensity to own wealth. For any individual, wage rate $w(t)$ and rate of interest $r(t)$ are given in markets and wealth $k(t)$ is predetermined before decision.

Maximizing $U(t)$ in (2.7) subject to the budget constraint (2.6) yields

$$
w(t) T_{h}(t)=\sigma \bar{y}(t), \quad c(t)=\xi \bar{y}(t), \quad s(t)=\lambda \bar{y}(t) .
$$

According to the definitions, the household's wealth in period $t+1$ is equal to the savings made in period $t$,

$$
k^{*}(t+1)=s(t)=\lambda \bar{y}(t) .
$$

We have thus completed building the model. We now analyze dynamic properties of the system.

\section{Equilibrium and stability}

This section examines dynamic properties of the system (2.9). First, from the definition of $\bar{y}(t)$ and (2.1), we obtain

$$
\bar{y}=\left(f^{\prime}(k)-\delta_{k}\right) k^{*}+\left(f(k)-k f^{\prime}(k)\right) T_{0}+k^{*} .
$$

Substituting this equation into $w(t) T_{h}(t)=\sigma \bar{y}(t)$ yields

$$
(\xi+\lambda)\left(f(k)-k f^{\prime}(k)\right) T_{0}=\left(f^{\prime}(k)+\delta\right) \sigma k^{*}+\left(f(k)-k f^{\prime}(k)\right) T,
$$

where we use (2.1) and $T(t)+T_{h}(t)=T_{0}$. Inserting $k^{*}(t)=T(t) k(t)$ into the above equation, we solve

$$
T(t)=\frac{\left(f(k)-k f^{\prime}(k)\right)(\xi+\lambda) T_{0}}{\left(f^{\prime}(k)+\delta\right) \sigma k+\left(f(k)-k f^{\prime}(k)\right)},
$$

where $\delta \equiv 1-\delta_{k}$ and $f-k f^{\prime}>0$ for any positive $k$. We see that for any positive $k, 0<$ $T(t)<T_{0}$. This also guarantees that

$$
0<T_{h}(t)\left(=T_{0}-T(t)\right)<T_{0}
$$

We see that $T(t)$ is uniquely determined as a function of $k(t)$. From $k^{*}(t)=T(t) k(t)$ and (2.9), we obtain

$$
T(t+1) k(t+1)=\lambda \bar{y}(t)
$$

Inserting $k^{*}(t)=T(t) k(t)$ and (3.1) into this equation, we obtain

$$
\Lambda_{0}((t+1)) k(t+1)=\Lambda(k(t))\left(f(k(t))-k(t) f^{\prime}(k(t))\right),
$$


where

$$
\begin{aligned}
\Lambda_{0}(k(t+1)) & \equiv \frac{\left(f(k(t+1))-k(t+1) f^{\prime}(k(t+1))\right)(\xi+\lambda)}{\left(f^{\prime}(k(t+1))+\delta\right) \sigma k(t+1)+\left(f(k(t+1))-k(t+1) f^{\prime}(k(t+1))\right)}, \\
\Lambda(k(t)) & \equiv\left[\frac{\left(f^{\prime}(k(t))+\delta\right) k(t)+\left(f(k(t))-k(t) f^{\prime}(k(t))\right)}{\left(f^{\prime}(k(t))+\delta\right) \sigma k(t)+\left(f(k(t))-k(t) f^{\prime}(k(t))\right)}\right] \lambda>0 .
\end{aligned}
$$

We calculate

$$
\begin{aligned}
\frac{d\left[k(t+1) \Lambda_{0}(k(t+1))\right]}{d k(t+1)}= & \frac{\left(f(k)-k f^{\prime}(k)\right) \Lambda_{0}(k)}{\left(f^{\prime}(k)+\delta\right) \sigma k+\left(f(k)-k f^{\prime}(k)\right)} \\
& -\frac{\sigma k^{2} f^{\prime \prime} \Lambda_{0}(k)\left(\left(f^{\prime}(k)+\delta\right) k+\left(f(k)-k f^{\prime}(k)\right)\right)}{\left(f(k)-k f^{\prime}(k)\right)\left[\left(f^{\prime}(k)+\delta\right) \sigma k+\left(f(k)-k f^{\prime}(k)\right)\right]}>0 .
\end{aligned}
$$

As $d\left(\Lambda_{0} k\right) / d k>0$ for any positive $k$, according to the implicit function theorem, from (3.6), we can express $k(t+1)$ as a function of $k(t)$ as follows:

$$
k(t+1)=\Lambda^{*}(k(t)),
$$

where $\Lambda^{*}(k)$ has the same degree of smoothness of $f^{\prime \prime}(k)$. The difference equation involves a single variable $k(t)$. With a positive initial condition, the one-dimensional difference equation determines $k(t)$ in any period of time.

Lemma 3.1. For any positive solution $k(t)$ of the difference equation (3.9), all the other variables are uniquely determined by the following procedure: $T(t)$ by $(3.3) \rightarrow T_{h}(t)=T_{0}-$ $T(t) \rightarrow k^{*}(t)=T(t) k(t) \rightarrow r(t)$ and $w(t)$ by $(2.1) \rightarrow \hat{y}(t)$ by $(2.4) \rightarrow \bar{y}(t)$ by $(2.6) \rightarrow c(t)$, and $s(t)$ by $(2.8) \rightarrow f(k(t)) \rightarrow F(t)=N(t) f(k(t))$.

Lemma 3.1 guarantees that once we determine dynamic properties of (3.9), we can determine the behavior of all the other variables in the system. Hence, it is sufficient for us to be concerned with (3.9).

By (3.6), an equilibrium point is given by

$$
\Lambda_{0}(k) k=\Lambda(k)\left(f(k)-k f^{\prime}(k)\right) .
$$

Inserting $\Lambda_{0}(k)$ and $\Lambda(k)$ into the above equation yields

$$
\frac{f(k)}{k}-\left(\frac{\xi}{\lambda}+\delta_{k}\right)=0
$$

The equation has a unique positive solution if $f^{\prime}(0)>\left(\xi / \lambda+\delta_{k}\right)$. With Lemma 3.1, we see that the system has a unique positive solution. We denote the equilibrium value of $k$ by $k^{*}$. To check stability of the unique equilibrium, we calculate $d \Lambda_{1} / d k$ at $k^{*}$. Taking derivatives of the two sides of the difference equation (3.6), we have

$$
\frac{d\left[\Lambda_{0}((t+1)) k(t+1)\right]}{d k(t+1)} \frac{d k(t+1)}{d k(t)}=\frac{d\left[\Lambda(k(t))\left(f(k(t))-k(t) f^{\prime}(k(t))\right)\right]}{d k(t)}, \quad \text { at } k=k^{*} .
$$


Substituting

$$
\begin{aligned}
\frac{d\left(k \Lambda_{0}\right)}{d k} & =\frac{\left(f-k f^{\prime}\right) \Lambda_{0}}{\left(f^{\prime}+\delta\right) \sigma k+\left(f-k f^{\prime}\right)}-\frac{\sigma k^{2} f^{\prime \prime} \Lambda_{0}\left(\left(f^{\prime}+\delta\right) k+\left(f-k f^{\prime}\right)\right)}{\left(f-k f^{\prime}\right)\left[\left(f^{\prime}+\delta\right) \sigma k+\left(f-k f^{\prime}\right)\right]}, \\
\frac{d \Lambda}{d k} & =\left[\frac{f^{\prime}+\delta}{\left(f^{\prime}+\delta\right) k+\left(f-k f^{\prime}\right)}-\frac{\left(\sigma f^{\prime}+\sigma \delta\right)-(\xi+\lambda) k f^{\prime \prime}}{\left(f^{\prime}+\delta\right) \sigma k+\left(f-k f^{\prime}\right)}\right] \Lambda
\end{aligned}
$$

into (3.12), we have

$$
F_{1}(k) \frac{d \Lambda_{1}}{d k}=F_{2}(k)
$$

in which

$$
\begin{gathered}
F_{1}(k) \equiv f-k f^{\prime}-\sigma k^{2} f^{\prime \prime}-\sigma k^{3} f^{\prime \prime} F^{*}, \quad F_{2}(k) \equiv \frac{(\xi+\lambda)\left(f^{\prime}+\delta\right) k}{\left(k F^{*}+1\right)}-\left(k F^{*}+1\right) \sigma k^{2} f^{\prime \prime}, \\
F^{*} \equiv \frac{f^{\prime}+\delta}{f-k f^{\prime}}
\end{gathered}
$$

at $k^{*}$. Using $f^{\prime}>0, f^{\prime \prime}<0$, and $f-k f^{\prime}>0$, we see that $F_{1}>0$ and $F_{2}>0$. It is straightforward to check that $F_{1}>F_{2}$. Hence, we conclude that

$$
\frac{d \Lambda_{1}}{d k}=\frac{F_{2}}{F_{1}} \in(0,1)
$$

This implies that the equilibrium point is stable.

Theorem 3.2. The dynamic system has a unique stable equilibrium.

\section{Comparative statics analysis}

We showed that the dynamic system has a unique stable equilibrium. We now examine impact of change in some parameters. First, we introduce technological change by specifying $f(k)=A h(k)$, where $A$ describes the level of technology. Taking derivatives of (3.11) with respect to $A$ yields

$$
\frac{d k}{d A}=\frac{k f}{\left(f-k f^{\prime}\right) A}>0,
$$

where $f / k-f^{\prime}>0$. As technology is improved, the capital intensity $k$ is increased. From (3.3), we obtain

$$
\frac{d T}{d A}=-\frac{\left(\left(f-k f^{\prime}\right) f^{\prime}+k f f^{\prime \prime}\right)(f+\delta k) k T \sigma}{A\left(f-k f^{\prime}\right)^{2}\left[\left(f^{\prime}+\delta\right) \sigma k+\left(f-k f^{\prime}\right)\right]} .
$$

The sign of $d T / d A$ is the same as that of $\left(f-k f^{\prime}\right) f^{\prime}+k f f^{\prime \prime}$. As $\left(f-k f^{\prime}\right) f^{\prime}>0$ and $k f f^{\prime \prime}<0$, the impact is ambiguous. If $f$ takes on the Cobb-Douglas form, that is, $f=$ $A k^{\alpha}$, then $d T / d A=0$. If the production function takes on the CES form $f=A\left(a k^{\rho}+\right.$ $1)^{1 / \rho}$, where $\rho<1, a$ and $A$ are positive, we calculate

$$
\left(f-k f^{\prime}\right) f^{\prime}+k f f^{\prime \prime}=a \rho A^{2} k^{\rho-1}\left(a k^{\rho}+1\right)^{2 / \rho-2} .
$$


We see that if $\rho>0$, then $d T / d A>0$; if $\rho=0$, then $d T / d A=0$; and if $\rho<0$, then $d T / d A<$ 0 . By $k^{*}=k T$, we have

$$
\frac{d k^{*}}{d A}=k \frac{d T}{d A}+T \frac{d k}{d A}
$$

If the improvement in technology increases work time, then per capita wealth definitely increases; otherwise, the impact is ambiguous. From (2.1), we obtain

$$
\frac{d r}{d A}=\frac{f^{\prime}}{A}+f^{\prime \prime} \frac{d k}{d A}, \quad \frac{d w}{d A}=\frac{w}{A}-k f^{\prime \prime} \frac{d k}{d A}>0
$$

The wage rate is increased due to technological improvement; but the impact on the rate of interest is ambiguous. The impact on the output level is given by

$$
\frac{d f}{d A}=\frac{f}{A}+f^{\prime} \frac{d k}{d A}>0
$$

We now examine impact of change in preference. As $\sigma+\xi+\lambda=1$, change in the propensity to consume leisure has to be associated with change in other propensities. For simplicity, we specify the preference change as follows: $d \sigma=-d \lambda$ and $d \xi=0$. Taking derivatives of (3.11) with respect to $\sigma$ yields

$$
\frac{d k}{d \sigma}=-\frac{\xi k^{2}}{\left(f-k f^{\prime}\right) \lambda^{2}}<0 .
$$

As the propensity to use leisure increases and the propensity to save declines, the capital intensity declines in the long term. It is important to note that if $d \sigma=-d \xi$ and $d \lambda=0$, then we have $d k / d \sigma>0$. That is, if the propensity to use leisure time increases and the propensity to consume declines, then the capital intensity increases. Another pattern of the preference is given by

$$
d \sigma=-d(\xi+\lambda), \quad \frac{d \xi}{\xi}=\frac{d \lambda}{\lambda} .
$$

In this case, we have $d k / d \sigma=0$. As preference may change in different ways, its impact on $k$ is dependent on the specified pattern of preference change. In what follows, we limit our discussion to the case of $d \sigma=-d \lambda$ and $d \xi=0$.

From (3.3), we obtain

$$
\begin{aligned}
\frac{1}{T} \frac{d T}{d \sigma}= & {\left[\frac{\left(f^{\prime}+\delta\right)\left(f-k f^{\prime}\right) \sigma-(f+\delta k) \sigma k f^{\prime \prime}}{\left[\left(f^{\prime}+\delta\right) \sigma k+\left(f-k f^{\prime}\right)\right]\left(f-k f^{\prime}\right)}\right] \frac{d k}{d \sigma}-\frac{1}{(\xi+\lambda)} } \\
& -\frac{\left(f^{\prime}+\delta\right) k}{\left(f^{\prime}+\delta\right) \sigma k+\left(f-k f^{\prime}\right)}<0 .
\end{aligned}
$$

We conclude that as the propensity to stay at home is increased, the time of staying at home increases. It should be remarked that this conclusion may not hold if we specify 
different patterns of preference change. By $k^{*}=k T$, we have

$$
\frac{d k^{*}}{d \rho}=k \frac{d T}{d \rho}+T \frac{d k}{d \rho}<0 .
$$

As the propensity to use leisure increases, per capita wealth declines in the long term. From (2.1), we obtain

$$
\frac{d r}{d \sigma}=f^{\prime \prime} \frac{d k}{d \sigma}>0, \quad \frac{d w}{d \sigma}=-k f^{\prime \prime} \frac{d k}{d \sigma}<0
$$

As the propensity to use leisure time increases, the wage rate falls and the rate of interest increases. The impact on the output level is given by

$$
\frac{d f}{d \sigma}=f^{\prime} \frac{d k}{d \sigma}>0
$$

\section{Conclusions}

We proposed a one-sector growth model with endogenous leisure. The model of fixed time is much influenced by the Solow model, the Ramsey model, and the Diamond model. The main deviation from the traditional approaches is that we proposed an alternative approach to the behavior of consumers. Our approach has a mechanism of endogenous saving which the Solow model does not have; it does not assume addition of utility over time as the Ramsey model asks for; and it does not assume that agents live only two periods as in the Diamond model. It provides a mechanism of endogenous savings and labor supply. The dynamics is one-dimensional as that of the Solow model. In comparison with the Ramsey approach which would lead to two-dimensional dynamics for a similar problem, the dimension in our approach is reduced-this advantage is evident when we model multiple groups of consumers. It should be mentioned that the utility function used in this study has been applied to different fields of economics by Zhang (e.g., $[7,8]$ ); but all these studies used the Cobb-Douglas production and utility functions in continuous time. This study may be considered as a generalization of these previous studies. Indeed, we may study many other dynamic issues of economic growth within the framework proposed in this study.

\section{References}

[1] C. Azariadis, Intertemporal Macroeconomics, Blackwell, Oxford, 1993.

[2] E. Burmeister and A. R. Dobell, Mathematical Theories of Economic Growth, Collier Macmillan Publishers, London, 1970.

[3] P. Diamond, National debt in a neoclassical growth model, Am. Econ. Rev. 55 (1965), no. 5, $1126-1150$.

[4] F. Ramsey, A mathematical theory of saving, Econom. J. 38 (1928), no. 152, 543-559.

[5] P. A. Samuelson, An exact consumption-loan model of interest with or without the social contrivance of money, J. Polit. Econ. 66 (1958), no. 6, 467-482.

[6] R. Solow, A contribution to the theory of economic growth, Quart. J. Econom. 70 (1956), no. 1, 65-94. 
[7] W. B. Zhang, Woman's labor participation and economic growth: creativity, knowledge utilization and family preference, Econom. Lett. 42 (1993), no. 1, 105-110.

[8] , Preference, structure and economic growth, Struct. Change Econ. Dynam. 7 (1996), no. 2, 207-221.

Wei-Bin Zhang: College of Asia Pacific Management, Ritsumeikan Asia Pacific University, 1-1 Jumonjibaru, Beppu City, Oita Prefecture 874-8577, Japan

E-mail address: wbz1@apu.ac.jp 


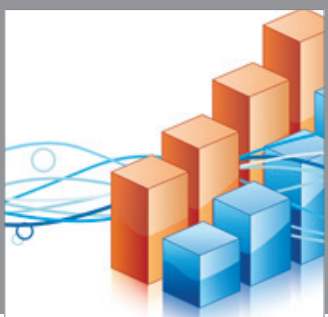

Advances in

Operations Research

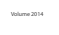

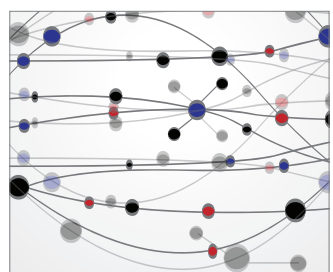

\section{The Scientific} World Journal
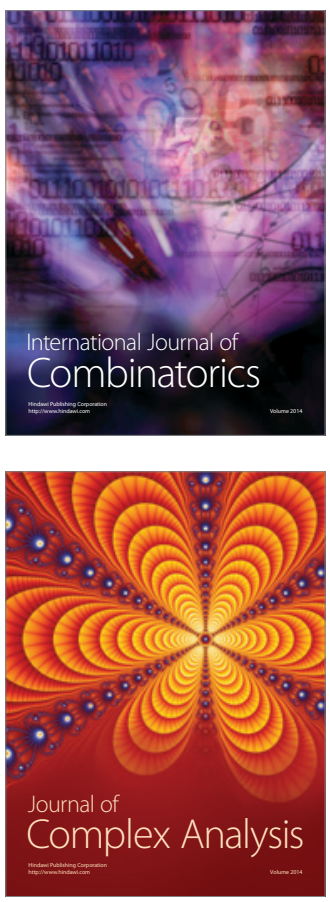

International Journal of

Mathematics and

Mathematical

Sciences
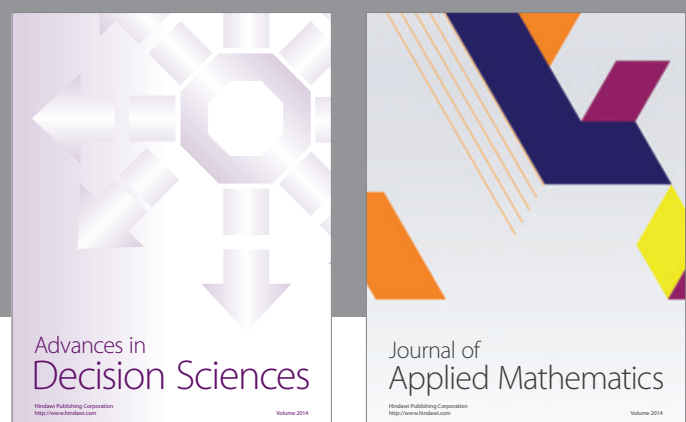

Journal of

Applied Mathematics
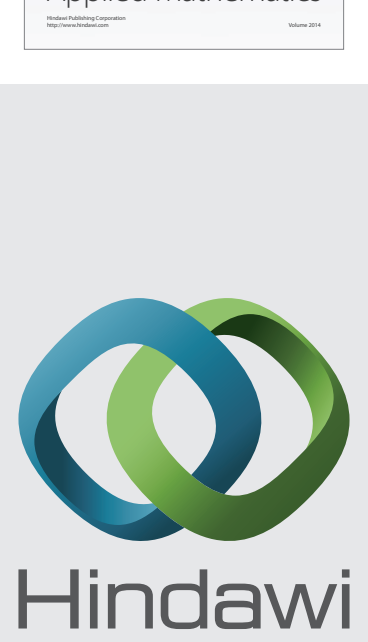

Submit your manuscripts at http://www.hindawi.com
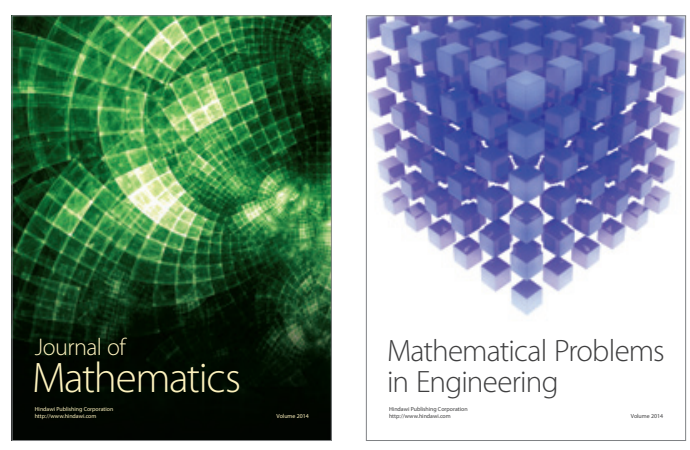

Mathematical Problems in Engineering
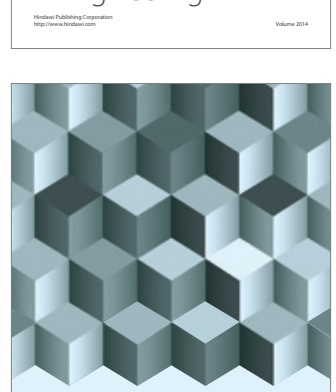

Journal of

Function Spaces
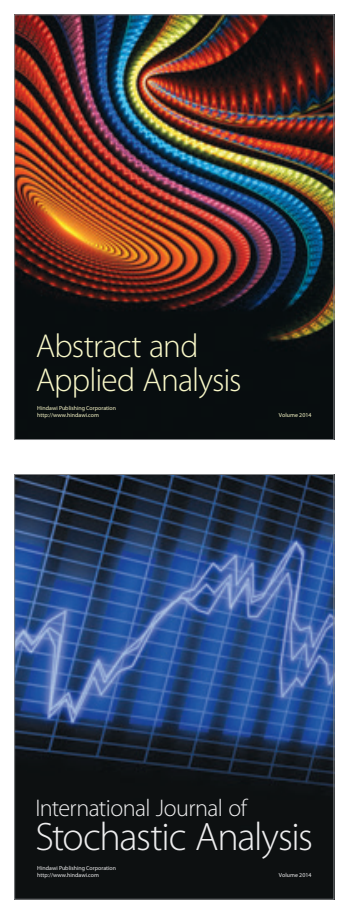

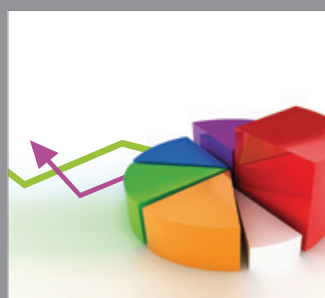

ournal of

Probability and Statistics

Promensencen
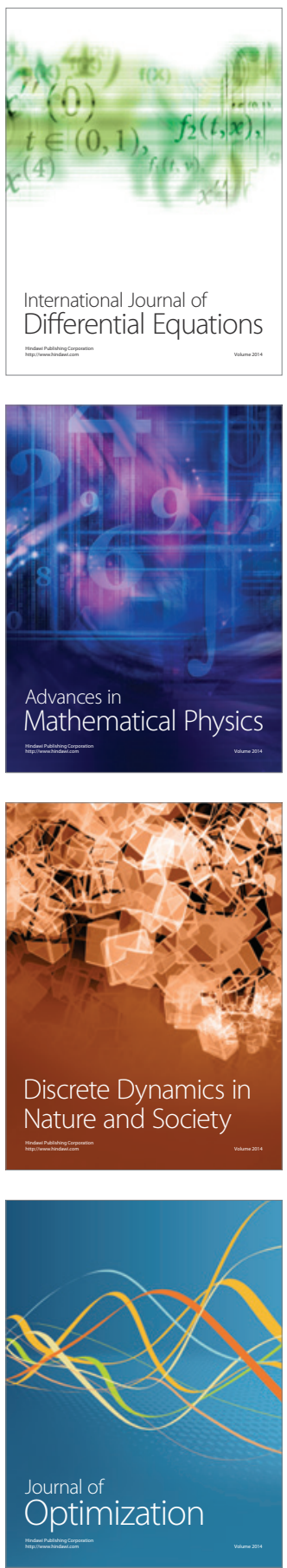